Article

\title{
Identification of Key Off-Flavor Compounds in Thermally Treated Watermelon Juice via Gas Chromatography-Olfactometry-Mass Spectrometry, Aroma Recombination, and Omission Experiments
}

\author{
Xiao Yang, Fan Yang, Ye Liu *, Jian Li and Huan-Lu Song \\ Beijing Engineering and Technology Research Center of Food Additives, School of Food and Health, Beijing \\ Technology and Business University, No. 11, Fucheng Road, Haidian District, Beijing 100048, China; \\ yxiaoyyy@163.com (X.Y.); 15733195507@163.com (F.Y.); lijian@th.btbu.edu.cn (J.L.); \\ songhl@th.btbu.edu.cn (H.-L.S.) \\ * Correspondence: liuye@th.btbu.edu.cn; Tel.: +86-010-6898-4034
}

Received: 5 February 2020; Accepted: 17 February 2020; Published: 20 February 2020

\begin{abstract}
Thermally treated watermelon juice (TW) presents a strong unpleasant smell, resulting in poor consumer acceptance. It is necessary to identify the key off-flavor compounds in TW. Solid-phase microextraction (SPME) and solvent-assisted flavor evaporation (SAFE) coupled with gas chromatography-olfactometry-mass spectrometry (GC-O-MS) were applied to the extraction and analysis of the volatile compounds in TW. Five aroma-active compounds and seven off-flavor compounds were quantitatively analyzed by the standard curve method. Based on the flavor dilution factor (FD), odor attribute, odor activity value (OAV) of volatile compounds, and partial least-squares regression (PLSR) analysis, seven key off-flavor compounds were preliminarily identified as follows: (E)-2-heptenal, decanal, octanol, diisopropyl disulfide, hexanol, (E)-2-decenal, and (E)-2-octenol. Aroma recombination proved that these off-flavor compounds above had a negative impact on the overall flavor in TW. Omission experiments were taken to confirm them further. Finally, octanol, diisopropyl disulfide, and (E)-2-decenal were identified as the most potent off-flavor compounds in TW.
\end{abstract}

Keywords: watermelon juice; thermal treatment; off-flavor; GC-O-MS; aroma recombination; omission

\section{Introduction}

Watermelon is a desirable fruit owing to its nutritional benefits. In China, the annual planting area and yield are approximately 1.85 million $\mathrm{hm}^{2}$ and 74.84 million tons, respectively, which accounts for $53.3 \%$ and $67.4 \%$ of the global production in 2017 [1]. Watermelon contains minerals, vitamins, and specific amino acids [2], and is especially rich in lycopene [3]. Consumption of lycopene-rich food may reduce the prevalence of certain types of cancers [4]. Hence, watermelon products have wide market potential.

Heating watermelon juice considerably affects its quality owing to its thermo-sensitive nature [5]. However, thermal treatment is a necessary step in industrial juice processing. The "steamed flavor" after thermal treatment affects consumer acceptance [6]. This considerably hinders the industrial processing of watermelon juice.

To identify the off-flavor compounds in thermally treated watermelon juice (TW), it is necessary to understand the mechanism of flavor change. Current studies have focused on the aroma of fresh watermelon (FW) or its juice. The flavor compounds in watermelon juice are mainly C6 and C9 aldehydes, ketones, and alcohols, such as nonanal, (E)-6-nonenol, (Z,Z)-2,6-nonadienal, 
(Z)-3-nonenal, (E,Z)-2,6-nonadienal, and (Z,Z)-3,6-nonadienal [7,8]. Development of off-flavor is an unavoidable issue in the thermal processing of watermelon juice; however, to the best of our knowledge, this is yet to be examined in TW. Investigations regarding off-flavors are mainly associated with other food materials. Dimethyl disulfide, dimethyl sulfide, dimethyl trisulfide, and 3-(methylthio) propanal contribute to the cooked flavor of melon juice during thermal processing [9]. The sulfur compounds and $C 5$ aldehydes accumulate in winter melon juice during boiling [10]. Sensory experiments have shown that 2-methoxy-4-vinylphenol and dimethyl sulfide contribute to the typical stale off-flavor in stored orange juice $\left(37^{\circ} \mathrm{C}\right.$ for four weeks) [11]. Hydrogen sulfide, dimethyl sulfide, methanethiol, and dimethyl trisulfide are important compounds contributing to cooked flavor in pasteurized milk [12].

In the present study, the aroma profiles of FW and TW were compared to identify the off-flavor compounds. The key off-flavor compounds in TW were determined using gas chromatography-olfactometry-mass spectrometry (GC-O-MS), odor attributes, and partial least-squares regression (PLSR) analysis. Furthermore, aroma recombination and omission experiments were performed to verify the key off-flavor compounds.

\section{Materials and Methods}

\subsection{Chemicals}

n-Alkanes (C7-C30) for the retention index (RI) calculation, 2-methyl-3-heptanone (99\%, internal standard), (E,Z)-2,6-nonadienal (95\%), (E)-2-heptenal (97\%), decanal ( $\geq 98 \%)$, octanol ( $\geq 99 \%)$, (E,Z)-2,6-nonadienol ( $\geq 95 \%)$, (E)-2-octenal ( $\geq 95 \%)$, diisopropyl disulfide ( $\geq 96 \%)$, hexanol $(\geq 99 \%)$, (E)-2-nonenal (97\%), (E)-2-decenal ( $\geq 95 \%)$, nonanol (98\%), and (E)-2-octenol (97\%) were purchased from Sigma-Aldrich (Beijing, China). Hexane, diethyl ether, n-pentane, and anhydrous $\mathrm{Na}_{2} \mathrm{SO}_{4}$ used for extraction and separation of flavor substances were all analytical reagent and provided by Banxia Scientific Instruments Co. Ltd. (Beijing, China).

\subsection{Preparation of Samples}

Qilin is the main cultivar with a large yield in China. Twenty watermelons (cultivar: Qilin, seedless, weighing approx. $0.4 \mathrm{~kg}$ each; locality of growth: Panggezhuang Town, Daxing District, Beijing) were one-time selected and purchased from Beijing Yonghui Supermarket randomly on June 10th, 2018. The pulp was blended (Philips, HR2860, Zhuhai, China), and quickly filtered through a nylon mesh (200 mesh). FW was analyzed immediately. Batches of $100 \mathrm{~mL}$ juice were vacuum-packed with an odorless vacuum packaging bag with aluminum foil immediately and frozen using liquid nitrogen. All the packed juices ( $100 \mathrm{~mL}$ for each bag) were stored at $-80{ }^{\circ} \mathrm{C}$ for further analysis. TW was processed using a water bath at $70{ }^{\circ} \mathrm{C}$ for $20 \mathrm{~min}$ according to the pasteurization method (the juice flavor changed greatly under this condition through the pre-experiments. A thermometer was inserted into the juice through the bag and timing began when the center temperature of juice reached $\left.70{ }^{\circ} \mathrm{C}\right)[13]$.

\subsection{Extraction of Flavor Compounds From Watermelon Juice by Solid-Phase Microextraction (SPME)}

Volatile organic compounds of a $10 \mathrm{~mL}$ sample of watermelon juice with $1 \mu \mathrm{L}$ internal standard (2-methyl-3-heptanone, $0.816 \mu \mathrm{g} / \mu \mathrm{L}$ ) added in a $40 \mathrm{~mL}$ headspace vial (Agilent, Inc., Santa Clara, CA, USA) were extracted manually with SPME using a $2 \mathrm{~cm}, 50 / 30 \mu \mathrm{m}$ divinylbenzene/carboxen/polydimethylsiloxane fiber (Supelco, Inc., Bellefonte, PA, USA). Samples were allowed to equilibrate for $20 \mathrm{~min}$ at $40{ }^{\circ} \mathrm{C}$ before collection for $40 \mathrm{~min}$ with continuous stirring at 100 rpm (J\&K Scientific Ltd., Beijing, China) [14].

\subsection{Extraction of Flavor Compounds From Watermelon Juice by Solvent-Assisted Flavor Evaporation (SAFE)}

One hundred milliliters of watermelon juice was mixed with $150 \mathrm{~mL}$ diethyl ether-pentane mixture $(2: 1, v / v)$ and stirred for $8 \mathrm{~h}$. Fifty microliters of 2-methyl-3-heptanone $(0.816 \mu \mathrm{g} / \mu \mathrm{L})$ were added as the 
internal standard. Then, volatiles were extracted from the solvent extracts by distillation for $2 \mathrm{~h}$ at $10^{-4}$ torr. The solvent layer was concentrated to $2 \mathrm{~mL}$ with a Vigreux column (Heqi Glass Instrument Co., Ltd, Shanghai, China) after being dried through an anhydrous $\mathrm{Na}_{2} \mathrm{SO}_{4}$ column. The volume further reduced to $0.2 \mathrm{~mL}$ under a flow of nitrogen [15].

\subsection{GC-O-MS Analysis}

GC-MS (7890A-7000B; Agilent Technologies Inc., Santa Clara, CA, USA) with an olfactometer (Sniffer 9000; Brechühler, Schlieren, Switzerland) was used to analyze the volatile compounds. DB-WAX and DB-5 chromatographic columns (30 $\mathrm{m} \times 0.25 \mathrm{~mm} \times 0.25 \mu \mathrm{m}$; J\&W Scientific, Folsom, CA, USA) were employed to separate these compounds [14].

Mass spectra in electron ionization mode were recorded at $70 \mathrm{eV}$ and a mass/charge range of 50-350 amu at a 2.0 scan s$^{-1}$ scan rate. Compounds were identified according to NIST 14.0 (The National Institute of Standards and Technology, Gaithersburg, MD, USA) mass spectra libraries.

GC-O analysis was carried out on polar and non-polar columns by three well-trained panelists. Before analysis, the panelists were trained by smelling the odors of the model solutions of reference compounds at different concentrations. The aroma descriptor, intensity value, and retention time were recorded by the panelists during analysis [15]. If two or more panelists detected the aroma, an aroma-active location was identified.

\subsection{Identification of Key Flavor Compounds}

Two types of dilution analysis were used to identify key flavor compounds, including headspace dilution analysis (HDA) for SPME and aroma extraction dilution analysis (AEDA) for SAFE, as described by Zhang et al. [15]. For SPME (Supelco, Inc., Bellefonte, PA, USA), the volatile compounds were diluted stepwise by increasing the split ratio of 1:3. For SAFE (Glasbläserei Wolfgang Bahr, Manching, Germany), the concentrated fraction was diluted stepwise at the ratio of 1:3 with a diethyl ether-pentane mixture $(2: 1, v / v)$. The process was ceased when aromas could not be smelled. FD factor could be expressed as the ratio of the initial and final concentration of the flavor compound of juice. The compounds with FD higher than 1 were identified as key flavor compounds.

\subsection{Qualitative Analysis of Flavor Compounds}

The compound identification was carried out by NIST 14.0 mass spectrum database, the retention index (RI), and odor properties. The key flavor compounds were confirmed further compared with the standard compounds. RI was calculated using Equation (1) and compared with the references.

$$
R I=100 n+100 \frac{t_{a}-t_{n}}{t_{n+1}-t_{n}}
$$

where $t \_a$ is the retention time of the sample " $a$ ", $t \_n$ is the retention time of $C n$, " $n$ " represents the number of carbon atoms, and the retention time of sample " $a$ " is between $\mathrm{Cn}$ and $\mathrm{Cn}+1$ [16].

\subsection{Quantitative Analysis of Flavor Compounds}

GC conditions were the same as mentioned above, and a selected ion monitor (SIM) was selected as the mass acquisition mode. Both extract methods were used to quantify different ions. Reference standards with a series of concentrations were prepared. The mixed reference standards $(1 \mu \mathrm{L})$ were added to the sample gathered with internal standard $(1 \mu \mathrm{L}, 0.816 \mu \mathrm{g} / \mu \mathrm{L})$. The extraction procedures were the same as the methods of SPME and SAFE as described above. Standard curves were established based on the peak area and concentration of each compound. The $Y$-axis represented the peak area ratio of analyte to the internal standard, and the $X$-axis represented the concentration 
of reference standards of the analyte [17]. In order to eliminate the loss during the extract process, the recovery of the target compound was calculated using Equation (2).

$$
\operatorname{Recovery}(\%)=\frac{\left(C_{1}-C_{0}\right)}{C_{2}} \times 100 \%
$$

where $C_{0}$ is the concentration of the compound before reference standard being added, $C_{1}$ is the detected concentration after reference standard being added, and $C_{2}$ is the reference standard concentration being added [16].

\subsection{Odor Activity Value (OAV)}

The equation to calculate $\mathrm{OAV}$ was as below:

$$
O A V=\frac{C_{i}}{O T_{i}}
$$

where $C_{i}$ is a compound concentration and $O T_{i}$ is the odor threshold of this compound. Compounds with $\mathrm{OAV} \geq 1$ were considered to contribute to the juice flavor [18].

\subsection{Sensory Evaluation}

Twelve panelists (6 males and 6 females, aged 20-35 years) were recruited from the Molecule Sensory Laboratory of Beijing Technology and Business University. Members of the sensory panel were trained for 2 months to familiarize the watermelon aroma characteristics. Sensory evaluation was strictly in accordance with Table 1 . The total score was based on the 5-point scale, with 0 for no odor and 5 for the strongest odor. Each sample was evaluated three times by every panelist to make sure that the score differences were no more than $20 \%$.

Table 1. Flavor attributes selected for sensory evaluation.

\begin{tabular}{cc}
\hline Flavor Attributes & Characteristic \\
\hline cucumber & fresh cucumber \\
grass & chopped freshly grass \\
fruity & mixed aroma associated with fresh fruit \\
floral & light aroma associated with fresh flowers \\
fatty & oily aroma like plant oils or animal fats \\
cooking & cooking smell with high temperature \\
green & pleasant aroma of fresh plant \\
\hline
\end{tabular}

\subsection{Aroma Recombination of TW}

To verify the obtained result of off-flavor compounds, the aroma recombination system was prepared and compared with the actual watermelon juice flavor [19]. A model aroma mixture system was prepared in ultrapure water containing $5 \%$ fructose and citric acid, $0.3 \%$ pectin, and reference standards of the five aroma-active compounds and seven key off-flavor compounds at the concentration were quantified. The total soluble solid of the model mixture was adjusted to $8.00 \pm 0.06 \mathrm{Brix}$, and $\mathrm{pH}$ $5.70 \pm 0.10$. The flavor similarity between the aroma recombination system and TW was compared based on the score rules of sensory evaluation listed in Table 1. Every sensory evaluation was conducted in triplicate.

\subsection{Omission Experiments}

Mixture models were produced by omitting one kind of key off-flavor compounds from the aroma recombination system. The same sensory panels evaluated the flavor similarity between the omission and recombination models in a triangle test. Every sensory evaluation was conducted in triplicate [19]. 


\subsection{Statistical Analysis}

Analysis of variance was carried out to determine the significance at a 95\% confidence interval using SAS 9.3 software (Statistical Analysis System, Cary, NC, USA). Partial least-squares regression (PLSR) was implemented using SIMCA-P 11.5 software (Umetrics, Umeå, Sweden). All experiments were performed in triplicate.

\section{Results and Discussion}

\subsection{Identification of Aroma-Active Compounds in FW and TW}

In order to extract and analyze the flavor compounds of watermelon juice comprehensively, the extract methods of SPME (non-solvent extract) and SAFE (solvent extract), the chromatographic columns of DB-Wax (strong polar) and DB-5 (weak polar) (Agilent Technologies Inc., Santa Clara, CA, USA) were applied in this study. Thus, the aroma-active compounds and key off-flavor compounds could be identified accurately and thoroughly. Fifty-seven compounds in FW and TW were extracted and identified (Table 2). Five groups of flavor compounds were identified in FW and TW, containing 26 aldehydes, 11 alcohols, 7 ketones, 5 sulfur compounds, and 8 others. Table 2 shows the presence of 17 compounds in total with FD $>1(7,9-11,13,14,16,17,27,29,33-36,39,47,48)$ by GC-O-AEDA of the isolates in FW and TW. Among the 17 detected compounds, 13 odorants (7, 9-11, 13, 14, 17, 27, 29, 34, $36,39,47)$ were present in both kinds of juices. Four compounds, including (E)-2-decenal, (E)-2-octenol, (E,Z)-3,6-nonadienol, and dipropyl trisulfide were only detected in TW, which contributed to the off-flavor of TW. 
Table 2. Flavor compounds identified by gas chromatography-olfactometry-mass spectrometry (GC-O-MS) in fresh watermelon (FW) and thermally treated watermelon juice (TW) extracted by solid-phase microextraction (SPME) and solvent-assisted flavor evaporation (SAFE).

\begin{tabular}{|c|c|c|c|c|c|c|c|c|c|}
\hline \multirow{2}{*}{ Categories } & \multirow{2}{*}{ Compounds ${ }^{a}$} & \multirow{2}{*}{ CAS } & \multirow{2}{*}{ Odor Property } & \multicolumn{2}{|c|}{ RI $^{b}$} & \multirow{2}{*}{$\begin{array}{l}\text { Identification } \\
\text { Methods }^{c}\end{array}$} & \multicolumn{2}{|c|}{ FD $^{d}$} & \multirow{2}{*}{$\begin{array}{l}\text { Extraction } \\
\text { Methods }\end{array}$} \\
\hline & & & & DB-WAX & DB-5 & & FW & TW & \\
\hline \multicolumn{10}{|l|}{ Aldehydes (26) } \\
\hline 1 & 2-methylbutanal & $96-17-3$ & cocoa, almond & 964 & 692 & MS,RI,S & - & - & SPME, SAFE \\
\hline 2 & hexanal & $66-25-1$ & grass & 1068 & 794 & MS,RI,S & - & - & SPME, SAFE \\
\hline 3 & (E)-2-pentenal ${ }^{\#}$ & $1576-87-0$ & strawberry, fruity & 1117 & 746 & MS,RI & - & - & SPME \\
\hline 4 & heptanal & $111-71-7$ & fatty, putrid & 1174 & 897 & MS,RI,S & - & - & SPME \\
\hline 5 & (E)-2-hexenal $\#$ & $6728-26-3$ & green, fruity & 1207 & 847 & MS,RI,S & - & - & SPME \\
\hline 6 & octanal & $124-13-0$ & pungent, soapy & 1280 & 998 & MS,RI,S & - & - & SPME, SAFE \\
\hline 7 & (E)-2-heptenal * & $18829-55-5$ & fatty, fruity, green & 1314 & 952 & $\mathrm{MS}, \mathrm{RI}, \mathrm{O}, \mathrm{S}$ & 27 & 81 & SPME \\
\hline 8 & nonanal & $124-19-6$ & green, fatty & 1383 & 1100 & MS,RI,S & - & - & SPME, SAFE \\
\hline 9 & $(E)$-2-octenal * & $2548-87-0$ & fatty, nut & 1420 & 1054 & $\mathrm{MS}, \mathrm{RI}, \mathrm{O}, \mathrm{S}$ & 27 & $>81$ & SPME, SAFE \\
\hline 10 & $(E, E)$-2,4-heptadienal * & $4313-03-5$ & nut, fatty & 1482 & - & MS,RI,O,S & 3 & 3 & SPME \\
\hline 11 & decanal & $112-31-2$ & pungent, soapy & 1490 & 1202 & $\mathrm{MS}, \mathrm{RI}, \mathrm{O}, \mathrm{S}$ & 81 & 81 & SPME \\
\hline 12 & benzaldehyde & $100-52-7$ & almond, caramel & 1509 & 957 & MS,RI,S & - & - & SPME, SAFE \\
\hline 13 & (E)-2-nonenal * & $18829-56-6$ & cucumber, green & 1527 & - & MS,RI,O,S & 27 & 27 & SPME, SAFE \\
\hline 14 & $(E, Z)-2,6$-nonadienal * & $557-48-2$ & cucumber, green & 1576 & - & $\mathrm{MS}, \mathrm{RI}, \mathrm{O}, \mathrm{S}$ & $>81$ & $>81$ & SPME \\
\hline 15 & $\beta$-cyclocitral & $432-25-7$ & mint & 1614 & 1222 & MS,RI & - & - & SPME \\
\hline 16 & (E)-2-decenal * & $3913-81-3$ & mechanical, soapy & 1635 & 1259 & MS,RI,O,S & - & 27 & SPME \\
\hline 17 & $(E, E)-2,4$-nonadienal & $5910-87-2$ & fatty, green & 1691 & 1192 & $\mathrm{MS}, \mathrm{RI}, \mathrm{O}, \mathrm{S}$ & 9 & 9 & SPME \\
\hline 18 & citral & $5392-40-5$ & lemon & 1726 & 1268 & MS,RI & - & - & SPME \\
\hline 19 & 2,6-dimethyl-5-heptenal & $106-72-9$ & fruity & - & 1050 & MS,RI & - & - & SPME \\
\hline 20 & (Z)-4-heptenal & $6728-31-0$ & cream & - & 892 & MS,RI & - & - & SPME \\
\hline 21 & 2-undecenal & $2463-77-6$ & sweet & - & 1346 & MS,RI & - & - & SPME \\
\hline 22 & undecanal & $112-44-7$ & fatty, sweet & - & 1303 & MS,RI & - & - & SPME, SAFE \\
\hline 23 & $(E, E)$-2,4-nonadienal & $25152-84-5$ & fried & 1802 & 1314 & MS,RI,S & - & - & SPME \\
\hline 24 & acetal & $105-57-7$ & fruity & 900 & 722 & MS,RI & - & - & SAFE \\
\hline 26 & dodecanal & $112-54-9$ & floral & - & 1405 & MS,RI & - & - & SAFE \\
\hline
\end{tabular}


Table 2. Cont.

\begin{tabular}{|c|c|c|c|c|c|c|c|c|c|}
\hline \multirow{2}{*}{ Categories } & \multirow{2}{*}{ Compounds ${ }^{a}$} & \multirow{2}{*}{ CAS } & \multirow{2}{*}{ Odor Property } & \multicolumn{2}{|c|}{$\mathbf{R I}^{b}$} & \multirow{2}{*}{$\begin{array}{l}\text { Identification } \\
\text { Methods }^{c}\end{array}$} & \multicolumn{2}{|c|}{$F^{d}$} & \multirow{2}{*}{$\begin{array}{c}\text { Extraction } \\
\text { Methods }\end{array}$} \\
\hline & & & & DB-WAX & DB-5 & & FW & TW & \\
\hline \multicolumn{10}{|l|}{ Alcohols (11) } \\
\hline 27 & hexanol & $111-27-3$ & bitter, floral & 1346 & 865 & $\mathrm{MS}, \mathrm{RI}, \mathrm{O}, \mathrm{S}$ & 81 & 81 & SPME, SAFE \\
\hline 28 & (Z)-3-hexenol & $928-96-1$ & grass & 1376 & 852 & $\mathrm{MS}, \mathrm{RI}$ & - & - & SPME, SAFE \\
\hline 29 & Octanol * & $111-87-5$ & metal, burnt & 1548 & 1068 & $\mathrm{MS}, \mathrm{RI}, \mathrm{O}, \mathrm{S}$ & 81 & 81 & SPME \\
\hline 30 & heptanol & $111-70-6$ & green & - & 967 & MS,RI,S & - & - & SPME \\
\hline 31 & 1-octene-3-ol & $3391-86-4$ & mushroom & 1394 & 977 & MS,RI,S & - & - & SPME \\
\hline 32 & benzyl alcohol & $100-51-6$ & floral & 1865 & 1037 & MS,RI & - & - & SPME, SAFE \\
\hline 33 & (E)-2-octenol * & 18409-17-1 & plastic, soapy & 1601 & 1167 & $\mathrm{MS}, \mathrm{RI}, \mathrm{O}, \mathrm{S}$ & - & 3 & SPME \\
\hline 34 & nonanol & 143-08-8 & fatty, green & 1650 & 1170 & $\mathrm{MS}, \mathrm{RI}, \mathrm{O}, \mathrm{S}$ & 27 & 27 & SPME, SAFE \\
\hline 35 & $(E, Z)-3,6$-nonadienol * & $56805-23-3$ & fishy & 1738 & - & $\mathrm{MS}, \mathrm{RI}, \mathrm{O}, \mathrm{S}$ & - & 3 & SPME, SAFE \\
\hline 36 & $(E, Z)-2,6$-nonadienol * & $28069-72-9$ & cucumber & 1754 & - & $\mathrm{MS}, \mathrm{RI}, \mathrm{O}, \mathrm{S}$ & 27 & 81 & SPME, SAFE \\
\hline 37 & 2-methylbutanol & $137-32-6$ & wine & - & 745 & MS,RI & - & - & SAFE \\
\hline \multicolumn{10}{|l|}{ Ketones (7) } \\
\hline 38 & 6-methyl-5-hepten-2-one & $110-93-0$ & rubbery & 1327 & 983 & MS,RI & - & - & SPME, SAFE \\
\hline 39 & geranyl acetone * & $3796-70-1$ & floral, green & 1844 & 1450 & $\mathrm{MS}, \mathrm{RI}, \mathrm{O}, \mathrm{S}$ & 3 & 9 & SPME, SAFE \\
\hline 40 & $(Z)-\beta$-ionone * & $79-77-6$ & oat, floral & 1931 & - & $\mathrm{MS}, \mathrm{RI}, \mathrm{O}, \mathrm{S}$ & & & SPME \\
\hline 41 & 3-octanone & $106-68-3$ & medicine, fatty & 1248 & - & MS,RI & - & - & SPME \\
\hline 42 & 2-butanone & $78-93-3$ & floral & 894 & - & MS,RI & - & - & SAFE \\
\hline 43 & 2-pentanone & $107-87-9$ & fruity & - & 684 & MS,RI,S & - & - & SAFE \\
\hline 44 & 2-hexanone & $591-78-6$ & ether & - & 729 & MS,RI & - & - & SAFE \\
\hline
\end{tabular}


Table 2. Cont.

\begin{tabular}{|c|c|c|c|c|c|c|c|c|c|}
\hline \multirow{2}{*}{ Categories } & \multirow{2}{*}{ Compounds $^{a}$} & \multirow{2}{*}{ CAS } & \multirow{2}{*}{ Odor Property } & \multicolumn{2}{|l|}{$\mathbf{R I}^{\mathbf{b}}$} & \multirow{2}{*}{$\begin{array}{l}\text { Identification } \\
\text { Methods }^{c}\end{array}$} & \multicolumn{2}{|c|}{ FD $^{d}$} & \multirow{2}{*}{$\begin{array}{l}\text { Extraction } \\
\text { Methods }\end{array}$} \\
\hline & & & & DB-WAX & DB-5 & & FW & TW & \\
\hline \multicolumn{10}{|l|}{ Sulfides (5) } \\
\hline 45 & diethyl disulfide & $110-81-6$ & pungent, garlic & 1206 & - & MS,RI & - & - & SAFE \\
\hline 46 & ethyl propyl disulfide & $30453-31-7$ & garlic & 1231 & 970 & MS,RI & - & - & SAFE \\
\hline 47 & diisopropyl disulfide * & $4253-89-8$ & garlic, sulfur & 1249 & 1016 & $\mathrm{MS}, \mathrm{RI}, \mathrm{O}, \mathrm{S}$ & 81 & 81 & SAFE \\
\hline 48 & dipropyl trisulfide & 6028-61-1 & vegetable, garlic & 1527 & 1231 & MS,RI,O,S & - & 3 & SAFE \\
\hline 49 & methyl propyl disulfide & $2179-60-4$ & sulfur, garlic & 1112 & - & MS,RI & - & - & SAFE \\
\hline \multicolumn{10}{|l|}{ Others (8) } \\
\hline 50 & 2-n-pentylfuran & $3777-69-3$ & fatty & 1220 & 988 & MS,RI,S & - & - & SPME \\
\hline 51 & ethyl acetate & $141-78-6$ & fruity & 884 & - & MS,RI & - & - & SAFE \\
\hline 52 & o-xylene & $95-47-6$ & floral & 1126 & 865 & MS,RI & - & - & SPME, SAFE \\
\hline 53 & meta-xylene & $108-38-3$ & plastic & 1119 & 856 & MS,RI & - & - & SPME, SAFE \\
\hline 54 & limonene & $5989-27-5$ & green, fruity & 1194 & - & MS,RI & - & - & SAFE \\
\hline 55 & naphthalene & $91-20-3$ & wax & 1733 & 1185 & MS,RI & - & - & SAFE \\
\hline 56 & styrene & $100-42-5$ & gasoline & - & 886 & MS,RI & - & - & SAFE \\
\hline 57 & 3-methylbutyric acid & $503-74-2$ & sweat & - & 909 & MS,RI,S & - & - & SAFE \\
\hline
\end{tabular}

a Compounds marked with "*" mean there were significant differences in the concentration between FW and TW; "\#" means the compounds were only detected in TW; b compounds were compounds were identified by MS spectra; $\mathrm{O}$, compounds were identified by sniffing; RI, compounds were identified by comparison to reference standards; $\mathrm{d}$ compounds marked with "-", which means the compound could not be identified by sniffing. 


\subsubsection{Aldehydes}

Among the 17 compounds identified in FW and TW, aldehydes were the most prevalent and potent aroma compounds in watermelon or its juice [7,8]. Of the 26 aldehydes, eight $(7,9-11,13,14,16$, 17 ) were the aroma-active compounds with FD $>1$. These aldehydes were responsible for imparting the soapy, fatty, or green smells. C6 and C9 unsaturated aldehydes are derived from polyunsaturated fatty acids (PUFA), such as linoleic acid and linolenic acid [7]. 9, 13-Hydroperoxides are primary PUFA oxidation products in plants. Herein, its decomposition by enzymes generated multiple fruity like aldehyde derivatives with shorter chains [7], such as (E)-2-nonenal, (E,Z)-2,6-nonadienal, (E)-2-decenal, and (E,E)-2,4-nonadienal. C9 unsaturated aldehydes are considered to contribute to melon aroma greatly due to their low odor thresholds [14]. Among melons, (E,E)-2,4-heptadienal and (E)-2-heptenal are reported in seedless watermelon and those from Ibaraki, Japan [20]. They are also present in the avocado, fish oil, and olive oil. These aldehydes derive from the oxidation of polyunsaturated fatty acids [21,22]. In these studies, (E)-2-heptenal imparts fatty, fruity, or green smell, and (E,E)-2,4-heptadienal contributes a green, fatty, or nutty note, which are in accordance with this study. (E)-2-Octenal was detected in grafted and mini-watermelon, and three cultivars of muskmelons $[8,20,23,24]$. Decanal was detected in Jiashi muskmelon, mini-watermelon, and heated soybean oil $[8,20,25,26]$. It easily contributes to subsequent reactions during the thermal treatment as a keto-enol tautomerism product of the combination product between 1-decenyl radical decomposed from O-8-hydroperoxide and hydroxyl radical [26]. Specifically, (E)-2-decenal only exists in TW $(\mathrm{FD}=27)$ with a mechanical and soapy smell. This contributed to the strong off-flavor of TW.

\subsubsection{Alcohols}

Eleven alcohols, six of which $(27,29,33-36)$ were identified with FD $>1$ in both FW and TW. Hexanol, octanol, (E)-2-octenol, nonanol, (E,Z)-3,6-nonadienol, and (E,Z)-2,6-nonadienol could be formed due to reduction of the corresponding aldehydes. All identified compounds were previously reported for watermelon aroma, and presented fatty, fruity, floral, green, or cucumber-like smell $[8,23]$. Among them, (E)-2-octenol and (E,Z)-3,6-nonadienol were only detected in TW (FD = 3 and 3) with plastic, soapy, or fishy smell slightly contributing to the off-flavor.

\subsubsection{Ketones}

Among the seven identified ketones, geranyl acetone was found with FD $>1$ in both FW and TW. They were reported in the melon fruits with different rootstocks, seedless watermelon, and watermelon juice treated by high-intensity pulsed electric fields $[6,14,23]$. Geranyl acetone probably derived from phytoene or phytofluene. In essence, color is highly associated with aroma compounds in watermelon, and this relationship is probably a function of the degradation of carotenoids into volatiles [27]. Moreover, its FD increased from three to nine, indicating that TW had a stronger floral or green smell than FW.

\subsubsection{Sulfides}

Five sulfides, diisopropyl disulfide, and dipropyl trisulfide were identified with FD $>1$ both in FW and TW. Few reports have described sulfides in watermelon or its juice, although these compounds exist in Jiashi muskmelon [25]. These two compounds were detected in our previous study, and extracted only by SAFE [28]. A strong possibility exists that the sulfur compounds may originate from methionine present in the watermelon seeds [29]. Sulfides presented the flavor characteristic of onion or garlic. They impacted the flavor quality of watermelon juice. Moreover, dipropyl trisulfide was only detected in TW $(F D=3)$ with vegetables or garlic smell, suggesting that it slightly contributes to the off-flavor.

As shown in Table 2, based on FDs, the aroma-active compounds in FW and TW are as follows: (E,Z)-2,6-nonadienal (FD >81/>81), (E)-2-octenal (FD = 27/>81), (E,Z)-2,6-nonadienol ( FD = 27/81), (E)-2-nonenal $(\mathrm{FD}=27 / 27)$, nonanol $(\mathrm{FD}=27 / 27)$. The results were in accordance with previous reports [28]. 


\subsection{Identification of Key Off-Flavor Compounds in TW}

Thermal treatment promoted the formation and release of flavor compounds with higher FDs in TW. After thermal treatment, watermelon juice produced a strong unpleasant flavor. As shown in Table 2, FDs of some compounds increased significantly after thermal treatment, including (E)-2-heptenal (fatty, fruity, green), (E)-2-octenal (fatty, nut), (E,E)-2,4-heptadienal (nut, fatty), (E)-2-nonenal (cucumber, green), (E,Z)-2,6-nonadienal (cucumber, green), (E)-2-decenal (mechanical, soapy), octanol (metal, burnt), (E)-2-octenol (plastic, soapy), (E,Z)-3,6-nonadienol (fishy), (E,Z)-2,6-nonadienol (cucumber), geranyl acetone (floral, green), (Z)- $\beta$-ionone (oat, floral), and diisopropyl disulfide (garlic, sulfur) [15]. Through the combination of FD values and odor characteristics, the compounds with unpleasant odor characteristics, and the FDs in TW being equal to or higher than that in FW, were identified as the off-flavor compounds. Thus, seven compounds were preliminary considered to be key off-flavors in TW: (E)-2-heptenal (fatty, fruity, green; FD = 81), decanal (pungent, soapy; FD = 81), octanol (metal, burnt; FD = 81), diisopropyl disulfide (garlic, sulfur; FD = 81), hexanol (bitter, floral; FD = 81), (E)-2-decenal (mechanical, soapy; FD = 27), and (E)-2-octenol (plastic, soapy; FD = 3).

As shown in Figure 1A, seven odor attributes were generally summarized in FW and TW. A pleasant odor, such as "cucumber", "grass", and "green" had higher scores in FW. While the scores of unpleasant odor, such as "cooking flavor" and "fatty", increased in TW significantly. This result was related to FDs increase in the following off-flavor compounds (Table 2): (E)-2-heptenal (fatty, fruity, green), (E)-2-decenal (mechanical, soapy), octanol (metal, burnt), (E)-2-octenol (plastic, soapy), and diisopropyl disulfide (garlic, sulfur). The off-flavor of TW was caused by the combination of multiple above compounds [30]. In thermally processed muskmelon juice, volatile sulfur compounds, and small molecular aliphatic aldehydes also contributed to the off-odors [31]. Methanethiol and dimethyl sulfide were the key off-flavor compounds identified in thermal mandarin juices [32]. Thermal degradation of sulfur-containing amino acids and unsaturated fatty acid, as well as Maillard reactions in juice, contributed to the generation of the thermal-induced off-notes $[33,34]$.

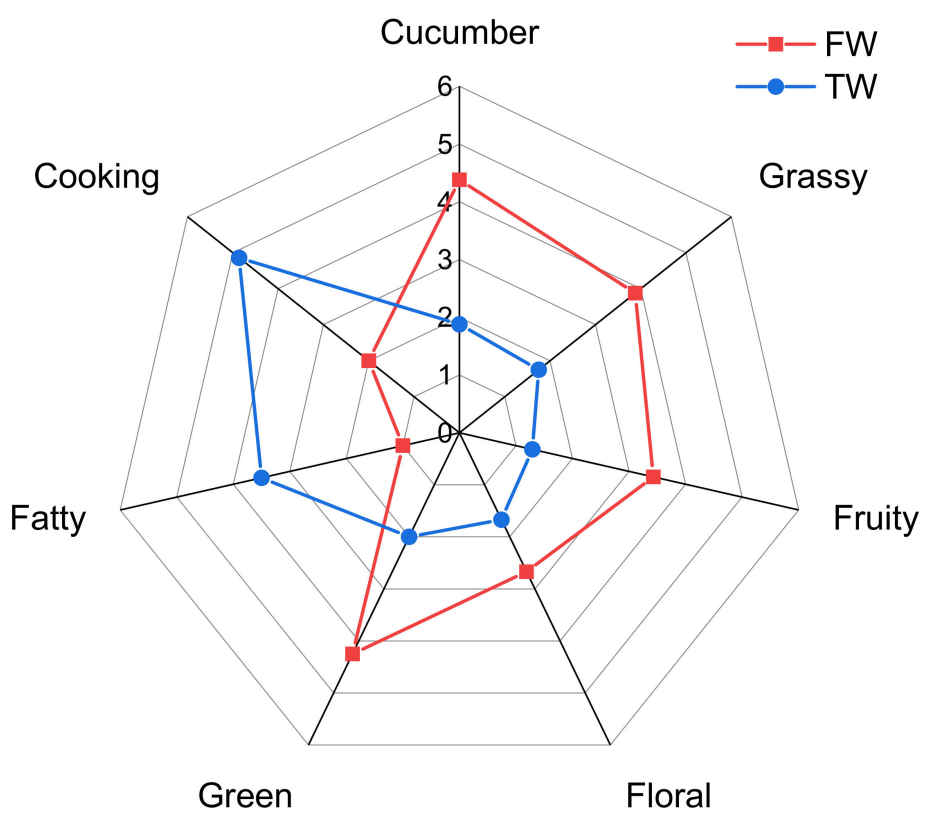

Figure 1. Cont. 


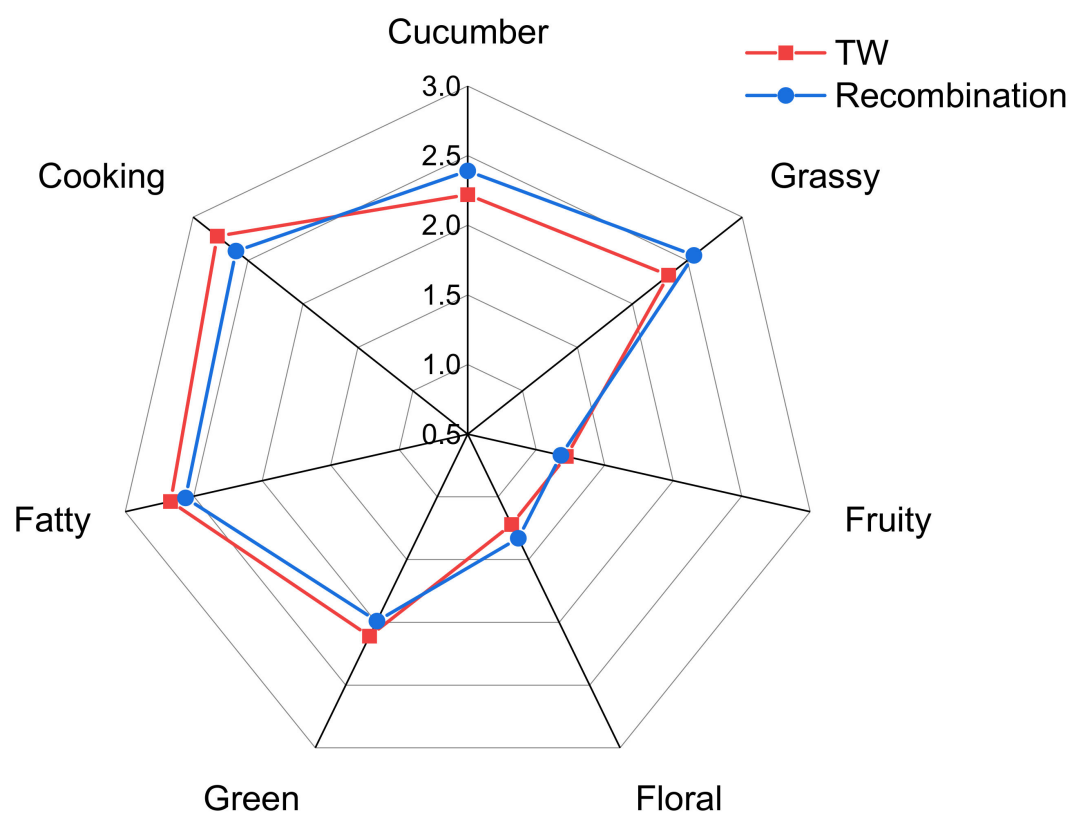

(B)

Figure 1. Odor attributes of FW and TW (A) and aroma profile of TW and recombination system (B) by sensory evaluation.

As shown in Figure 2, 7 flavor attributes and 12 compounds (aroma-active compounds and key off-flavor compounds) in FW and TW were selected to conduct PLSR analysis, they were taken as variable $X$ and $Y$, respectively. The PLSR model provided a two-factor model explaining $69 \%$ of the $\mathrm{X}$-variance (flavor attributes) and $63 \%$ of the Y-variance (aroma-active compounds and key off-flavor compounds) in Figure 2.

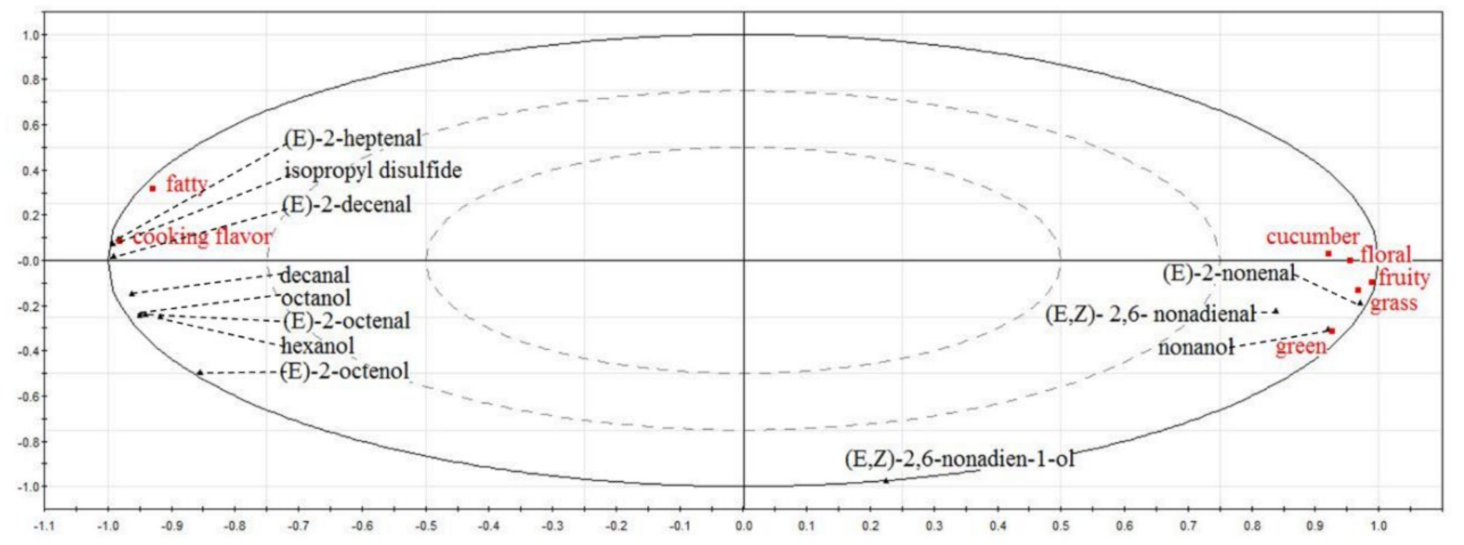

X-expl: 42\%, 27\%; Y-expl: 45\%, 18\%

Figure 2. Correlationship analysis of odor attributes and aroma-active compounds in FW and TW by partial least-squares regression (PLSR). 
The odor attributes of "fatty" and "cooking flavor" concentrated on the left side of the loading plot, which presented significant positive correlations with compounds: (E)-2-heptenal, diisopropyl disulfide, (E)-2-decenal, decanal, (E)-2-octenol, octanol, and hexanol $(p<0.05)$. In summary, these seven volatile compounds were preliminarily identified as the key off-flavor compounds in TW.

\subsection{OAV of Aroma-Active and Off-Flavor Compounds}

Three quantitative ions were selected in order to correctly match with known compounds from the quality library. The recovery $(70-130 \%)$ was calculated to guarantee the accuracy of the quantitative results (Table 3). The standard curves possess good linearity with correlation coefficient: $R^{2} \geq 0.99$. All data displayed improved repeatability with RSD $\leq 10 \%$. The concentration of five aroma-active compounds and seven off-flavor compounds are shown in Table 3. Among them, diisopropyl disulfide had the highest concentration $(2122.17 \mu \mathrm{g} / \mu \mathrm{L})$, followed by $(\mathrm{E})-2$-heptenal $(1090.23 \mu \mathrm{g} / \mu \mathrm{L})$ and (E,Z)-2,6-nonadienol (825.18 $\mu \mathrm{g} / \mu \mathrm{L})$.

OAV was another index that contributed aroma compounds to the overall flavor [18]. As shown in Table 4, the highest OAV in TW was diisopropyl disulfide (OAV =21,222), followed by (E)-2-nonenal $(\mathrm{OAV}=3146)$ and $(\mathrm{E}, \mathrm{Z})-2,6$-nonadienal $(\mathrm{OAV}=656)$. Ten compounds with $\mathrm{OAV} \geq 1$ contributed to the overall flavor of watermelon juice, which was in accordance with FDs. However, hexanol and (E)-2-octenol had higher FDs $(81$ and $>81)$ and lower OAV (OAV $<1)$ due to lower concentration or higher threshold. In the real food matrix, different odor compounds interact due to the antagonistic and synergistic effect, not a simple superposition [35]. Individual differences were completely unavoidable, including perception and cognition of flavor compounds. For OAV, every compound had the same psychometric function and aroma intensity, which increased linearly with increasing concentration [36]. However, the results contradicted the real matrix. The relationship between compound concentration and its response was not linear but S-shaped [24]. Hence, the identification of the key off-flavor compounds needed further verification. 
Table 3. Standard curve and concentrations of aroma-active and key off-flavor compounds in TW.

\begin{tabular}{|c|c|c|c|c|c|c|c|c|}
\hline No. & Key Flavor Compounds ${ }^{a}$ & FD & Quantitative Ion (m/z) & Standard Curve & $R^{2 \mathrm{~b}}$ & Concentration $(\mu \mathrm{g} / \mathrm{L})^{c}$ & Recovery (\%) & $\operatorname{RSD}(\%)^{d}$ \\
\hline 1 & (E)-2-octenal * & $>81$ & $108.2,83.1,70.1$ & $y=0.6813 x+0.1175$ & 0.9995 & 654.47 & 126 & 4.94 \\
\hline 2 & $(E, Z)-2,6$-nonadienal * & $>81$ & $109.1,70.1,67.1$ & $y=0.8418 x+0.0274$ & 0.9934 & 459.54 & 112 & 4.86 \\
\hline 3 & (E)-2-heptenal & 81 & $112.0,83.1,70.1$ & $y=0.2955 x+0.0183$ & 0.9959 & 1090.23 & 111 & 6.08 \\
\hline 4 & Decanal $\#$ & 81 & $209.0,193.0,70.1$ & $y=0.2869 x-0.0088$ & 0.9921 & 93.37 & 99 & 0.23 \\
\hline 5 & Octanol ${ }^{\#}$ & 81 & $96.9,84.1,69.0$ & $y=0.5663 x+0.0091$ & 0.9992 & 259.1 & 82 & 6.04 \\
\hline 6 & $(E, Z)-2,6$-nonadienol * & 81 & $122.2,81.0,69.1$ & $y=0.4322 x-0.0065$ & 0.9928 & 825.18 & 87 & 7.83 \\
\hline 7 & diisopropyl disulfide ${ }^{\#}$ & 81 & $150.1,108.0,66.0$ & $y=2.2337 x+0.6887$ & 0.9974 & 2122.17 & 72 & 0.99 \\
\hline 8 & Hexanol & 81 & $134.1,119.0,56.2$ & $y=0.8208 x+0.0072$ & 0.9985 & 18.68 & 98 & 8.97 \\
\hline 9 & (E)-2-nonenal * & 27 & $122.0,83.1,70.1$ & $y=0.8483 x+0.1171$ & 0.9919 & 597.69 & 114 & 5.79 \\
\hline 10 & (E)-2-decenal ${ }^{\#}$ & 27 & $136.0,83.1,70.1$ & $y=0.6988 x+0.1383$ & 0.9929 & 293.72 & 121 & 7.34 \\
\hline 11 & Nonanol * & 27 & $182.0,70.1,50.1$ & $\mathrm{y}=1.2630 \mathrm{x}+0.0130$ & 0.9983 & 17.77 & 77 & 8.71 \\
\hline 12 & $(E)-2$-octenol ${ }^{\#}$ & 3 & $146.8,81.1,57.2$ & $y=0.2583 x+0.0231$ & 0.9939 & 16.73 & 109 & 0 \\
\hline
\end{tabular}

a "*” means they were the aroma-active compounds; "\#" means they were the key off-flavor compounds; b correlation coefficient of standard curve; $\mathrm{c}$ average concentration of triplicate experiments; d relative standard deviation. 
Table 4. Odor activity values (OAV) of aroma-active and key off-flavor compounds.

\begin{tabular}{cccc}
\hline No. & Key Flavor Compounds & Threshold $(\mu \mathrm{g} / \mathrm{L})^{\mathbf{a}}$ & OAV \\
\hline 7 & diisopropyl disulfide & $0.1[37]$ & 21,222 \\
9 & $(E)-2-$-nonenal & $0.19[38]$ & 3146 \\
2 & $(E, Z)-2,6$-nonadienal & $0.7[38]$ & 656 \\
6 & $(E, Z)-2,6$-nonadienol & $1.3[38]$ & 635 \\
10 & $(E)-2$-decenal & $1[39]$ & 294 \\
1 & $(E)$-2-octenal & $3[39]$ & 218 \\
4 & decanal & $0.9[40]$ & 104 \\
3 & $(E)-2$-heptenal & $13[41]$ & 84 \\
11 & nonanol & $2[40]$ & 9 \\
5 & octanol & $110[39]$ & 2 \\
8 & hexanol & $500[42]$ & $<1$ \\
12 & $(E)$-2-octenol & $40[42]$ & $<1$ \\
\hline
\end{tabular}

\subsection{Aroma Recombination of TW}

According to the quantitative results of TW, the aroma recombination was carried out to verify the contribution of the seven key off-flavor compounds to the overall flavor of TW. As shown in Figure $1 \mathrm{~B}$, the aroma recombination system performance displayed good similarity with TW, with no significant difference between the seven odor attributes $(p<0.05)$ being observed. This indicated that the identification and quantitation experiments were accurate, and that the aroma-active and key off-flavor compounds were precisely identified [14,43]. Therefore, (E)-2-heptenal, diisopropyl disulfide, (E)-2-decenal, decanal, (E)-2-octenol, octanol, and hexanol were confirmed as the key off-flavor compounds in TW.

\subsection{Omission Experiments}

In order to further verify and rank the contribution level among the seven key off-flavor compounds, omission experiments were divided into seven groups (Table 5). When octanol was omitted, 12 sensory panelists judged the flavor difference correctly from three samples, which showed the highest significant difference $(p \leq 0.001)$. This result revealed that octanol played a very important role in the overall flavor in TW. Among them, the absence of diisopropyl disulfide and (E)-2-decenal showed significant differences ( $p \leq 0.05$ and $p \leq 0.01$ ), which agreed with the higher FDs and OAVs, respectively. Therefore, these two compounds also had a significant influence on the overall flavor of TW. The omission experiments: hexanol and (E)-2-octenol (OAV $\leq 1$ but higher FDs) also showed significance differences $(p \leq 0.01$ and $p \leq 0.05)$. However, no significant differences were observed when (E)-2-heptenal and decanal were omitted from the recombination in spite of their higher FDs and OAVs. Comprehensive consideration of significance difference of omission experiment, FD, and OAV, octanol (metal, burnt; FD = 81; OAV = 2), diisopropyl disulfide (garlic, sulfur; FD = 81; OAV = 21,222), and (E)-2-decenal (mechanical, soapy; $\mathrm{FD}=27 ; \mathrm{OAV}=294$ ) were identified as the most potent off-flavor compounds in TW. 
Table 5. Omission experiments from complete recombinate.

\begin{tabular}{cccc}
\hline No. Compounds Omitted from the Complete Recombinate & $\boldsymbol{n}^{\mathbf{b}}$ & Significance $^{\mathbf{c}}$ \\
\hline 1 & $(E)$-2-heptenal & 4 & \\
2 & decanal & 5 & \\
3 & octanol & 10 & $* * *$ \\
4 & diisopropyl disulfide & 8 & $*$ \\
5 & hexanol & 9 & $* *$ \\
6 & $(E)$-2-decenal & 8 & $* *$ \\
7 & $(E)$-2-octenol & 8 & $*$ \\
\hline
\end{tabular}

a Reference standards for preliminary determination of seven key off-flavor compounds; b Number of correct judgments from 12 sensory panelists who evaluated the flavor difference by the triangle test; $c$ "*", significant $(p \leq 0.05) ; “ * * *$, highly significant $(p \leq 0.01) ; “ * * * *$, very highly significant $(p \leq 0.001)$.

The above three compounds were previously reported as off-flavor compounds. Octanol contributes to the off-flavor of whey protein concentrate during storage of $45^{\circ} \mathrm{C}$ for 15 weeks, and it changes the organoleptic properties of packaged food [44,45]. In bovine bone marrow extract, it contributes to the off-flavor due to the Maillard reaction [46]. From this aspect, the Maillard reaction might also induce the off-flavor. (E)-2-decenal was employed as an aroma marker of oxidation degradation to quantitatively monitor and describe the quality of packaged olive oil [47]. (E)-2-Decenal also formed by oleic acid being degraded at $140{ }^{\circ} \mathrm{C}$ affects the flavor of frying $[48,49]$. It is derived from the thermal reaction of enzymatic hydrolysates of the protein with oxidized lard [50]. Diisopropyl disulfide showed a positive relationship with the sensory attributes "salt flavor" and "carrot aroma" in the commercial regular salt soup, and also a "sulfury, onion" note in the preserved egg yolk $[15,51]$. These results are in accordance with this study.

\section{Conclusions}

In conclusion, seven key off-flavor compounds in TW were preliminarily identified by concentration variation, odor attributes, and PLSR analysis. Five aroma-active compounds and seven key off-flavor compounds were quantified by the standard curve method. They were further confirmed by both OAV and FD. The aroma recombination was employed to verify the contribution of the seven key off-flavor compounds to the overall aroma profile. In addition, the omission experiment from the recombination system was carried out to confirm the results. Octanol, diisopropyl disulfide, and (E)-2-decenal were identified as the most potent off-flavor compounds in TW.

Author Contributions: X.Y. carried out the laboratory work and performed statistical analysis; F.Y. collected samples, drafted, and revised the manuscript; Y.L. conceived, designed, and coordinated the study; J.L. and H.-L.S. helped to edited and revised the manuscript. All authors have read and agreed to the published version of the manuscript.

Funding: This research was funded by National Natural Science Foundation of China, grant number 31871821 and the APC was funded by National Natural Science Foundation of China, grant number 31871821.

Conflicts of Interest: There are no conflicts of interest to declare.

\section{References}

1. Food and Agriculture Organization (FAO). STAT 2017. Available online: http://www.fao.org/faostat/zh/ \#data/QC (accessed on 3 February 2019).

2. Tarazona-díaz, M.; Viegas, J.; Moldao-martins, M.; Aguayo, E. Bioactive compounds from flesh and by-product of fresh-cut watermelon varieties. J. Sci. Food Agric. 2011, 91, 805-812. [CrossRef] [PubMed]

3. Ellis, A.C.; Dudenbostel, T.; Crowe-White, K. Watermelon juice: A novel functional food to increase circulating lycopene in older adult women. Plant Food Hum. Nutr. 2019, 74, 200-203. [CrossRef]

4. Giovannucci, E. A review of studies of tomatoes, lycopene, and prostate cancer. Exp. Biol. Med. 2002, 227, 852-859. [CrossRef] 
5. Liu, Y.; Hu, X.S.; Zhao, X.Y.; Song, H.L. Combined effect of high pressure carbon dioxide and mild heat treatment on overall quality parameters of watermelon juice. Innov. Food Sci. Emerg. 2012, 13, 112-119. [CrossRef]

6. Aguiló-Aguayo, I.; Montero-Calderón, M.; Soliva-Fortuny, R.; Martín-Belloso, O. Changes on flavor compounds throughout cold storage of watermelon juice processed by high-intensity pulsed electric fields or heat. J. Food Eng. 2010, 100, 43-49.

7. Xisto, A.L.R.P.; Boas, E.V.d.B.V.; Nunes, E.E.; Federal, B.M.V.B.; Guerreiro, M.C. Volatile profile and physical, chemical, and biochemical changes in fresh cut watermelon during storage. Food Sci. Technol. Campinas 2012, 32, 173-178. [CrossRef]

8. Fredes, A.; Sales, C.; Barreda, M.; Valcárcel, M.; Roselló, S.; Beltrán, J. Quantification of prominent volatile compounds responsible for muskmelon and watermelon aroma by purge and trap extraction followed by gas chromatography-mass spectrometry determination. Food Chem. 2016, 190, 689-700. [CrossRef]

9. Luo, D.S.; Pang, X.L.; Xu, X.X.; Bi, S.; Zhang, W.T.; Wu, J.H. Identification of cooked off-flavor components and analysis of their formation mechanisms in melon juice during thermal processing. J. Agric. Food Chem. 2018, 66, 5612-5620. [CrossRef]

10. Sun, X.X.; Baldwin, E.A.; Plotto, A.; Manthey, J.A.; Duan, Y.P.; Bai, J.H. Effects of thermal processing and pulp filtration on physical, chemical and sensory properties of winter melon juice. J. Sci. Food Agric. 2017, 97, 543-550. [CrossRef]

11. Averbeck, M.; Schieberle, P. Influence of different storage conditions on changes in the key aroma compounds of orange juice reconstituted from concentrate. Eur. Food Res. Technol. 2011, 232, 129-142. [CrossRef]

12. Al-Attabi, Z.; D'Arcy, B.R.; Deeth, H.C. Volatile sulfur compounds in pasteurised and UHT milk during storage. Dairy Sci. Technol. 2014, 94, 241-253. [CrossRef]

13. Ji, H.F.; Ni, H.; Chen, F.; Cai, H.N.; Yang, Y.F.; Xiao, A.F. Effects of pasteurization on the volatiles and aroma of Guanxi Pummelo juice. J. Chin. Inst. Food Sci. Technol. 2015, 15, 225-232.

14. Liu, Y.; He, C.C.; Song, H.L. Comparison of fresh watermelon juice aroma characteristics of five varieties based on gas chromatography-olfactometry-mass spectrometry. Food Res. Int. 2018, 107, 119-129. [CrossRef]

15. Zhang, Y.; Liu, Y.P.; Yang, W.X.; Huang, J.; Liu, Y.Q.; Huang, M.Q.; Sun, B.G.; Li, C.L. Characterization of potent aroma compounds in preserved egg yolk by gas chromatography-olfactometry, quantitative measurements, and odor activity value. J. Agric. Food Chem. 2018, 66, 6132-6141. [CrossRef]

16. Liang, J.J.; Xie, J.C.; Hou, L.; Zhao, M.Y.; Zhao, J.; Cheng, J.; Wang, S.; Sun, B.G. Aroma constituents in Shanxi aged vinegar before and after aging. J. Agric. Food Chem. 2016, 64, 7597-7605. [CrossRef]

17. Sgorbini, B.; Cagliero, C.; Liberto, E.; Rubiolo, P.; Bicchi, C.; Cordero, C. Strategies for accurate quantitation of volatiles from foods and plant-origin materials: A challenging task. J. Agric. Food Chem. 2019, 67, 1619-1630. [CrossRef]

18. Zhou, Q.; Jia, X.; Yao, Y.Z.; Wang, B.; Wei, C.Q.; Zhang, M. Characterization of the aroma-active compounds in commercial fragrant rapeseed oils via monolithic material sorptive extraction. J. Agric. Food Chem. 2019, 67, 11454-11463. [CrossRef]

19. Zheng, Y.; Sun, B.G.; Zhao, M.M.; Zheng, F.P.; Huang, M.Q.; Sun, J.Y.; Sun, X.T.; Li, H.H. Characterization of the key odorants in Chinese zhima aroma-type Baijiu by gas chromatography-olfactometry, quantitative measurements, aroma recombination, and omission studies. J. Agric. Food Chem. 2016, 64, 5367-5374. [CrossRef]

20. Dima, G.; Tripodi, G.; Condurso, C.; Verzera, A. Volatile constituents of mini-watermelon fruits. J. Essent. Oil Res. 2014, 26, 323-327. [CrossRef]

21. Vandamme, J.; Nikiforov, A.; Dujardin, K.; Leys, C.; Cooman, L.D.; Durme, J.V. Critical evaluation of non-thermal plasma as an innovative accelerated lipid oxidation technique in fish oil. Food Res. Int. 2015, 72, 115-125. [CrossRef]

22. Galvao, M.S.; Nunes, M.L.; Cdnstant, P.B.L.; Narain, N. Identification of volatile compounds in cultivars barker, collinson, fortuna and geada of avocado (Persea americana, Mill.) fruit. Food Sci. Technol. 2016, 36, 439-447. [CrossRef]

23. Condurso, C.; Verzera, A.; Dima, G.; Tripodi, G.; Crinò, P.; Paratore, A.; Romano, D. Effects of different rootstocks on aroma volatile compounds and carotenoid content of melon fruits. Sci. Hortic. 2012, 148, 9-16. [CrossRef] 
24. Pang, X.L.; Hu, X.S.; Liao, X.J.; Sun, Z.J.; Zhang, M.W.; Wu, J.H. Study on Two Evaluation methods of odor-active compounds in Hami melon: Frequency detection-gas chromatography-olfactometry method and odor activity value analysis. J. Chin. Inst. Food Sci. Technol. 2012, 12, 174-182.

25. Pang, X.L.; Guo, X.F.; Qin, Z.H.; Yao, Y.B.; Hu, X.S.; Wu, J.H. Identification of Aroma-Active Compounds in Jiashi Muskmelon Juice by GC-O-MS and OAV Calculation. J. Agric. Food Chem. 2012, 60, 4179-4185. [CrossRef]

26. Zhang, Q.; Qin, W.; Lin, D.R.; Shen, Q.; Saleh, A.S.M. The changes in the volatile aldehydes formed during the deep-fat frying process. J. Food Sci. Technol. 2015, 52, 7683-7696. [CrossRef] [PubMed]

27. Zepka, L.Q.; Garruti, D.S.; Sampaio, K.L.; Mercadante, A.Z.; Da Silva, M.A.A.P. Aroma compounds derived from the thermal degradation of carotenoids in a cashew apple juice model. Food Res. Int. 2014, 56, 108-114. [CrossRef]

28. Liu, Y.; He, C.C.; Song, H.L. Comparison of SPME versus SAFE processes for the analysis of flavor compounds in watermelon juice. Food Anal. Method 2018, 11, 1677-1689. [CrossRef]

29. Dash, P.; Ghosh, G. Fractionation, amino acid profiles, antimicrobial and free radical scavenging activities of Citrullus lanatus seed protein. Nat. Prod. Res. 2017, 31, 2945-2947. [CrossRef]

30. Zhang, Y.; Song, H.L.; Li, P.; Yao, J.; Xiong, J. Determination of potential off-flavour in yeast extract. LWT-Food Sci. Technol. 2017, 82, 184-191. [CrossRef]

31. Pang, X.L.; Zhang, Y.Z.; Qiu, J.; Cao, J.M.; Sun, Y.Q.; Li, H.H.; Kong, F.Y. Coupled multidimensional GC and odor activity value calculation to identify off-odors in thermally processed muskmelon juice. Food Chem. 2019, 301, 125307-125317. [CrossRef]

32. Cheng, Y.J.; Rouseff, R.; Li, G.J.; Wu, H.J. Methanethiol, an off-flavor produced from the thermal treatment of mandarin juices: A study of citrus sulfur volatiles. J. Agric. Food Chem. 2020, 68, 1030-1037. [CrossRef]

33. Gassenmeier, K.; Schieberle, P. Formation of the intense flavor compound trans-4,5-epoxy-(E)-2-decenal in thermally treated fats. J. Oil Fat Ind. 1994, 71, 1315-1319.

34. Josephson, D.B.; Lindsay, R.C.; Stuiber, D.A. Biogenesis of lipid-derived volatile aroma compounds in the emerald shiner (Notropis atherinoides). J. Agric. Food Chem. 1985, 32, 1347-1352. [CrossRef]

35. Ntalli, N.G.; Ferrari, F.; Giannakou, I.; Menkissoglu-Spiroudi, U. Synergistic and antagonistic interactions of terpenes against Meloidogyne incognita and the nematicidal activity of essential oils from seven plants indigenous to Greece. Pest Manag. Sci. 2011, 67, 341-351. [CrossRef]

36. Baldovini, N.; Filippi, J.J. Identification of odor active constituents in natural raw materials. In Springer Handbook of Odor; Büttner, A., Ed.; Springer International Publishing AG: Cham, Switzerland, 2017; pp. $39-62$.

37. Fors, S. Sensory properties of volatile Maillard reaction products and related compounds. In ACS Symposium Series; Waller, G.R., Feather, M.S., Eds.; American Chemical Society: Washington, DC, USA, 1983; Volume 215, pp. 303-338.

38. Ullrich, F.; Grosch, W. Identification of the most intense odor compounds formed during autoxidation of methyl linolenate at room temperature. J. Am. Oil Chem. Soc. 1988, 65, 1313-1317. [CrossRef]

39. Butter, R.G.; Teranishi, R.; Ling, L.C.; Turnbaugh, J.G. Quantitative and sensory studies on tomato paste volatiles. J. Agr. Food Chem. 1990, 38, 336-340. [CrossRef]

40. Karahadian, C.; Johnson, K.A. Analysis of headspace volatiles and sensory characteristics of fresh corn tortillas made from fresh masa dough and spray-dried masa flour. J. Agr. Food Chem. 1993, 41, 791-799. [CrossRef]

41. Maarse, H. Volatile Compounds in Foods and Beverages; CRC Press: Boca Raton, FL, USA, 1991.

42. Josephson, D.B.; Lindsay, R.C.; Stuiber, D.A. Volatile carotenoid-related oxidation compounds contributing to cooked salmon flavor. LWT-Food Sci. Tech. 1991, 24, 425-432.

43. Steinhaus, M.; Sinuco, D.; Polster, J.; Osorio, C.; Schieberle, P. Characterization of the key aroma compounds in pink guava (Psidium guajava L.) by means of aroma re-engineering experiments and omission tests. J. Agric. Food Chem. 2009, 57, 2882-2888. [CrossRef]

44. Javidipour, I.; Qian, M.C. Volatile component change in whey protein concentrate during storage investigated by headspace solid-phase microextraction gas chromatography. Dairy Sci. Technol. 2008, 88, 95-104. [CrossRef]

45. Vera, P.; Canellas, E.; Nerín, C. Compounds responsible for off-odors in several samples composed by poly propylene, polyethylene, paper and cardboard used as food packaging materials. Food Chem. 2020, 309, 125792-125800. [CrossRef] 
46. Xu, X.R.; Zheng, Y.Y.; Song, H.L.; Gong, L.; Pan, W.Q. The effects of enzymatic hydrolysis degree of bovine bone marrow extract on flavor generation via the Maillard reaction. J. Food Meas. Charact. 2019, 13, 521-535. [CrossRef]

47. Antonis, K.; Pilar, H.M.; Frank, C.; Susan, S. Oxidation derived flavor compounds as quality indicators for package olive oil. J. Am. Oil Chem. Soc. 2004, 81, 251-257.

48. Chen, H.J.; Wang, Y.; Cao, P.R.; Liu, Y.F. Thermal oxidation rate of oleic acid increased dramatically at $140{ }^{\circ} \mathrm{C}$ studied using electron spin resonance and GC-MS/MS. J. Am. Oil Chem. Soc. 2019, 96, 937-944. [CrossRef]

49. Liu, Y.; Li, J.W.; Cheng, Y.J.; Liu, Y.F. Effect of frying oils fatty acid profile on quality, free radical and volatiles over deep-frying process: A comparative study using chemometrics. LWT Food Sci. Technol. 2019, 101, 331-341. [CrossRef]

50. Zhao, M.Y.; Zhao, J.; Xie, J.C.; Xiao, Q.F.; Fan, M.D.; Wang, T.Z.; Du, W.B.; Wang, M.; Guo, X.Y. Characterization of aroma compounds in two meat flavorings prepared from thermal reaction of enzymatic hydrolysates of black pig and common white pig meat proteinss with oxidized lard. Food Sci. 2017, 38, 40-47.

51. Mitchell, M.; Brunton, N.P.; Wilkinson, M.G. Impact of salt reduction on the instrumental and sensory flavor profile of vegetable soup. Food Res. Int. 2011, 44, 1036-1043. [CrossRef]

(C) 2020 by the authors. Licensee MDPI, Basel, Switzerland. This article is an open access article distributed under the terms and conditions of the Creative Commons Attribution (CC BY) license (http://creativecommons.org/licenses/by/4.0/). 